\title{
Thermal, Structural, and Physical Properties of Freeze Dried Tropical Fruit Powder
}

\author{
K. A. Athmaselvi, ${ }^{1}$ C. Kumar, $^{2}$ M. Balasubramanian, ${ }^{3}$ and Ishita Roy ${ }^{1}$ \\ ${ }^{1}$ Department of Food Process Engineering, Faculty of Engineering and Technology, SRM University, \\ Kattankulathur, Tamil Nadu 603203, India \\ ${ }^{2}$ Department of Physics, Government Arts College, Nandanam, Chennai, Tamil Nadu 600035, India \\ ${ }^{3}$ Valliammai Engineering College, Kattankulathur, Tamil Nadu 603203, India
}

Correspondence should be addressed to K. A. Athmaselvi; athmaphd@gmail.com

Received 1 August 2014; Revised 19 October 2014; Accepted 19 October 2014; Published 22 December 2014

Academic Editor: Raquel P. Guiné

Copyright (C) 2014 K. A. Athmaselvi et al. This is an open access article distributed under the Creative Commons Attribution License, which permits unrestricted use, distribution, and reproduction in any medium, provided the original work is properly cited.

\begin{abstract}
This study evaluates the physical properties of freeze dried tropical (guava, sapota, and papaya) fruit powders. Thermal stability and weight loss were evaluated using TGA-DSC and IR, which showed pectin as the main solid constituent. LCR meter measured electrical conductivity, dielectric constant, and dielectric loss factor. Functional groups assessed by FTIR showed presence of chlorides, and $\mathrm{O}-\mathrm{H}$ and $\mathrm{N}-\mathrm{H}$ bonds in guava, chloride and $\mathrm{C}-\mathrm{H}$ bond in papaya, and chlorides, and $\mathrm{C}=\mathrm{O}$ and $\mathrm{C}-\mathrm{H}$ bonds in sapota. Particle size and type of starch were evaluated by X-ray diffraction and microstructure through scanning electronic microscopy. A semicrystalline profile and average particle size of the fruit powders were evidenced by X-ray diffraction and lamellar/spherical morphologies by SEM. Presence of A-type starch was observed in all three fruits. Dependence of electric and dielectric properties on frequency and temperature was observed.
\end{abstract}

\section{Introduction}

Guava (Psidium guajava L.) and sapota (Manilkara zapota) are native of tropical America and grow well in tropical and subtropical regions and are widely cultivated in the tropics including India, Guatemala, and Mexico [1,2]. Papaya (Carica papaya L.) is also an important fruit crop grown widely in tropical and subtropical countries in the world. The relative humidity and temperature are the more critical variables to extend the shelf-life of the fruit and to preserve its sensory, physical, and chemical properties. Thus, dehydration processes may be an efficient alternative for fruit storage, because the reduction of water activity is related to the decline of chemical and enzymatic reactions responsible for the deterioration of foods. Dehydration is based on the extraction of water contained in foods up to a minimal level which is enough to their conservation for long time. The hot airdrying is one of the most used methods for preservation of fruits since long time ago; however the main problem is the possibility to lose or change some of their properties due to the thermal treatment. Hence, gentle drying techniques, such as osmodehydration or lyophilisation (freeze-drying), have also been used in fruits. With the aim to find new alternatives for the commercialization of tropical fruits and to reduce the difficulties for its handling and transport, freezedrying techniques were used to obtain added-value solids from tropical fruits.

The International Confederation for Thermal Analysis and Calorimetry (ICTAC) has defined thermal analysis (TA) as a group of techniques that allow us to study the relationship between material properties of a sample and its temperature. The use of TG analyses in these applications also allows us to determine at what temperatures and after what times drying is completed and at what point thermal degradation of the food material will occur. DSC is also used for the evaluation of quality parameters of vegetable oil and assessing oxidative deterioration of oil [3-5]. de Rosa et al. [6] studied the thermal stability of okra fibres by thermogravimetric analysis and reported that TG curve of okra fibres shows three weight loss steps, whilst their decomposition occurs in 
two main stages. Osorio et al. [1] studied thermal stability of guava (Psidium guajava K.) powders obtained by two dehydration methods, hot air-drying and freeze-drying, and thermal analysis curves showed some differences between hot air dried and freeze dried powder.

A lot of work has been done for studying the electrical and dielectric properties of various food items and food ingredients at microwave frequencies by Sipahioglu and Barringer [7], Sipahioglu et al. [8], Soltani et al. [9], Sharma and Prasad [10], and many others, but there is no significant amount of work on the study of these properties for tropical fruits at very low frequency levels $(0.001 \mathrm{MHz}$ to $10 \mathrm{MHz})$. Li et al. [11] measured moisture content of cookies using dielectric spectroscopy. Nelson and Datta [12] measured the dielectric constant and loss factor with an open-ended coaxial line probe and an impedance analyzer on external surfaces and internal tissue of four cultivars of miniature watermelons provided new permittivity data over a range of maturities at frequencies from $10 \mathrm{MHz}$ to $1.8 \mathrm{GHz}$ at $24^{\circ} \mathrm{C}$. They reported that both the dielectric constant and loss factor of internal tissues decreased monotonically with increasing frequency showing the dominance of ionic conduction at lower frequencies and dipolar losses at the higher frequencies. Mizukami et al. [13] measured moisture content of tea leaves using electrical impedance and capacitance method. This study attempts to develop relationship between the frequency and electrical and dielectric properties of spray-dried, pelletized powder of guava, sapota, and papaya.

The structural studies of the fruit powders were done using X-ray diffraction (XRD), scanning electron microscope (SEM), and Fourier transformer IR-spectroscopy (FTIR). $\mathrm{XRD}$ was used to reveal the presence and characteristics of crystalline structure of starch granules. Conventional laboratory analysis of fruit juices such as chemical testing is generally laborious and time consuming. But FTIR can be employed as a rapid and nondestructive method to identify different functional groups and molecules which can fingerprint a food.

Theivasanthi and Alagar [14] studied the XRD of Jackfruit Seed and reported diffraction peaks at around $15^{\circ}, 17^{\circ}, 23^{\circ}$, $31^{\circ}$, and $38^{\circ}$. Deraman et al. [15] have used XRD to study fiber of oil palm empty fruit bunch and rubberwood for medium-density fiberboard. Rengsutthi and Charoenrein [16] analyzed the jack fruit seed starch using XRD and reported that the XRD was used to reveal the presence and characteristics of crystalline structures of starch granules. Leopold et al. [17] used FTIR for quantitative determination of carbohydrates, such as glucose, fructose, and sucrose, in 28 processed commercial fruit juices and 5 genuine juices obtained from squeezed fruits. The objective of this study was to determine the thermal, dielectric, and structural properties of freeze dried fruit powders of guava, sapota, and papaya fruit.

\section{Materials and Methods}

2.1. Preparation of Samples. Fruits of similar size, color, and ripeness were selected for dehydration studies. Selected fruits were washed with tap water, peeled, destoned, and crushed to pulp. The pulp was transferred to the freeze dryer plate and it is spread uniformly and kept in the deep freezer for pretreatment $(12 \mathrm{~h})$ and then it is freeze dried for $12 \mathrm{~h}$ at $-52^{\circ} \mathrm{C}$ and -3 mbar pressure.

\subsection{Differential Scanning Calorimetry (DSC) and Thermo-} gravimetric Analysis (TGA). The DSC and TGA studies were conducted for the fruit powder samples. In TGA, the weight loss of fruit powder was measured at different temperature. The DSC measures the temperatures and heat flows associated with test sample as a function of time and temperature in a controlled atmosphere. These measurements provide quantitative and qualitative information about physical and chemical changes that involve endothermic or exothermic processes or changes in heat capacity. In the present study, the DSC and TGA measurements were made in the temperature range $0^{\circ}$ to $1000^{\circ} \mathrm{C}$ with heating range $20^{\circ} \mathrm{C} / \mathrm{min}$ using SDT Q600 V8.0 Build 95 instrument. This differential scanning calorimeter has a temperature accuracy of $\pm 0.2^{\circ} \mathrm{C}$ temperature reproducibility $\pm 0.1^{\circ} \mathrm{C}$. Since the DSC was interfaced with computer, the recorded spectrum is obtained from the computer [18].

2.3. Dielectric Constant and Electrical Conductivity. Pellets were prepared from the freeze dried tropical fruit powder. To perform dielectric study, the surface of the pellets was smoothened. The polished surface was maintained as highly smooth as possible for a good electrode contact. Platinum paint was used as the electrode and it was pasted on both sides of the test sample (pellet disc). The test sample was placed in copper conducting sample holder and the electrode connections were taken from the surfaces of the test sample and connected to the analyzer. The whole setup was placed inside a tubular furnace in which the temperature was gradually increased by a periodical adjustment of dimmer stat. The dielectric measurements were carried out using a two-probe LCR meter of ANDO AG4311B type analyzer up to $160^{\circ} \mathrm{C}$ for various frequency ranges [19].

2.4. FTIR Analysis. Fourier transformed infrared spectra absorption for each sample was obtained using a Bruker Alpha Model. The samples gently mixed with micronized $\mathrm{KBr}$ powder and compressed into pellets at a force of $10 \mathrm{KN}$ for 2 min using a manual tablet presser at room temperature. The data were recorded at room temperature in the wavelength range of $4000-500 \mathrm{~cm}^{-1}$.

2.5. X-Ray Diffraction. The XRD analysis of the powder samples was done in PANalytical Xpert Pro XRD instrument in powder mode with the source being $\mathrm{Cu}-\mathrm{K} \alpha$ radiation at $1.540 \AA$. The spectra were scanned at a diffraction angle $(2 \theta)$ range of $5-80^{\circ}$ at a step size of $0.05^{\circ} /$ step and $2 \mathrm{sec} / \mathrm{step}$ [20].

2.6. SEM Analysis. The SEM analysis was done on FEI Quanta-FEG 200 SEM. The experiment was done at low vacuum at 80 torr, each fruit powder sample was mounted on a stub using a carbon-tape, and field emission was done at $5 \mathrm{kV}[1]$. 


\section{Result and Discussion}

3.1. Differential Scanning Calorimetry and Thermogravimetric Analysis. A thermogravimetric measuring unit consists mainly of a sensitive weighing balance that is placed within an oven. During a temperature-time program in the oven, the weight of the sample is measured and recorded over time. The oven atmosphere is nitrogen. At high temperatures, volatile substances are driven off, and a decrease in sample mass is observed and measured. DSC plot is sometimes called a thermogram. In thermodynamic systems analysis, heat taken up by a system (gain) is considered positive, while heat given up (loss) is considered negative. It is likewise with heat flow, in which heat flowing into a system is positive (endothermic) and heat flowing out is negative (exothermic).

Thermal stability of freeze dried fruit powder was investigated by thermogravimetric analysis. The TGA-DSC curve of guava, sapota, and papaya fruit powder is shown in Figure 1.

The TGA curves of guava powder show three general regions of weight loss (54.37-178.23, 178.23-305.28, and $\left.305.28-360.96^{\circ} \mathrm{C}\right)$. The first region $\left(54.37-178.23^{\circ} \mathrm{C}\right)$ reveals a weight loss around $6.714 \%$. This drop of mass can be assumed as water loss during the temperature rise. A double stage of mass drop for the guava powder in the second mentioned region $\left(178.23-305^{\circ} \mathrm{C}\right)$ related to a possible more complex volatilization of matter. The third region $\left(305.28-360.96^{\circ} \mathrm{C}\right)$ in the TGA analyses shows a more stable stage after volatilization of water and other compounds; between 150 and $350^{\circ} \mathrm{C}$ dehydroxylation, demethoxylation, and decarboxylation reactions should be occurring on pectin and similar polysaccharides (pectin is the main component of dehydrated guava) [21-23]. The total loss of weight for samples is $69.52 \%$ at $545^{\circ} \mathrm{C}$; the residue left after incineration at $980^{\circ} \mathrm{C}$ is $14.32 \%$, indicating the thermal stability of guava powder. On the other hand, DSC curves show that endothermic peak, centered at $68.64^{\circ} \mathrm{C}, 208.66^{\circ} \mathrm{C}, 341.16^{\circ} \mathrm{C}$, and $500.75^{\circ} \mathrm{C}$, involves the volatilization processes of water, melting of pectin contained in guava, and a possible demethoxylation, dehydroxylation, and decarboxylation of pectin and other polysaccharides [1].

The TGA curves of sapota powder show three general regions of weight loss $(54.85-180.20,180.20-332.76$, and $\left.332.76-372.17^{\circ} \mathrm{C}\right)$. The first region $\left(54.85-180.20^{\circ} \mathrm{C}\right)$ reveals a weight loss of $10.13 \%$. This drop of mass can be assumed as water loss during the temperature rise. The second region $\left(180.20-332.76^{\circ} \mathrm{C}\right)$ shows a weight loss of $38.17 \%$; the third region $\left(332.76-372.17^{\circ} \mathrm{C}\right)$ shows a weight loss of $16.95 \%$. The total weight loss of the sapota powder is $65.25 \%$ at $372.12^{\circ} \mathrm{C}$; the residue left after incinerations at $784.37^{\circ} \mathrm{C}$ is $3.192 \%$. The residual weight of sapota is much less when compared to guava powder. On the other hand, DSC curves show exothermic peak centered at $71.77^{\circ} \mathrm{C}, 209.09^{\circ} \mathrm{C}, 283.77^{\circ} \mathrm{C}$, $341.58^{\circ} \mathrm{C}$, and $358.44^{\circ} \mathrm{C}$. Similar trend is also seen in okra fiber [24].

The TGA curves of papaya powder show three general regions of weight loss (63.08-184.93, 184.93-314.30, and $\left.314.30-346.13^{\circ} \mathrm{C}\right)$. The first region $\left(63.08-184.93^{\circ} \mathrm{C}\right)$ reveals a weight loss of $11.25 \%$. This drop of mass can be assumed as water loss during the temperature rise. The second region

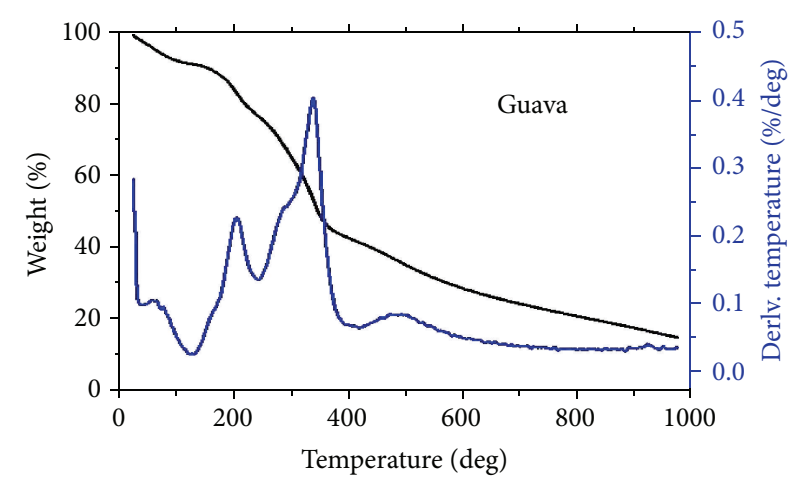

(a)

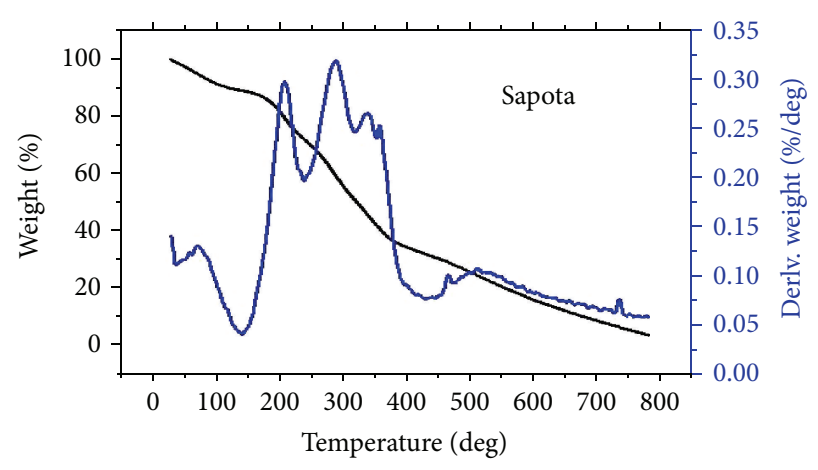

(b)

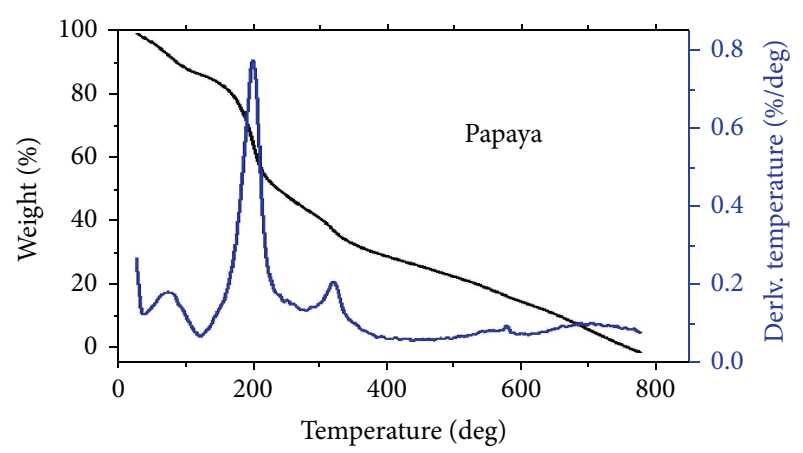

(c)

Figure 1: TGA-DSC of guava (a), sapota (b), and papaya (c).

$\left(184.93-314.30^{\circ} \mathrm{C}\right)$ shows a weight loss of $41.45 \%$; the third region $\left(332.76-372.17^{\circ} \mathrm{C}\right)$ shows a weight loss of $14.26 \%$. The total weight loss of the papaya powder is $73.45 \%$ at $589.55^{\circ} \mathrm{C}$; the residue left after incinerations at $761.95^{\circ} \mathrm{C}$ is $0.4389 \%$. The residual weight of papaya is much less when compared to guava powder. On the other hand, DSC curves show exothermic peak centered at $83.82^{\circ} \mathrm{C}, 205.47^{\circ} \mathrm{C}, 325.92^{\circ} \mathrm{C}$, and $581.28^{\circ} \mathrm{C}$

3.2. Frequency Dependence of Electrical Conductivity. Electrical conductivity $\left(\mathrm{S} \mathrm{m}^{-1}\right)$, dielectric constants, and dielectric loss factor values plotted versus different frequencies for guava, sapota, and papaya are given in Figure 2.

All the three fruits showed very low electrical conductivity at frequency between $0.001 \mathrm{MHz}$ and $1 \mathrm{MHz}$. However, after $1 \mathrm{MHz}$, the electrical conductivities increased sharply. 

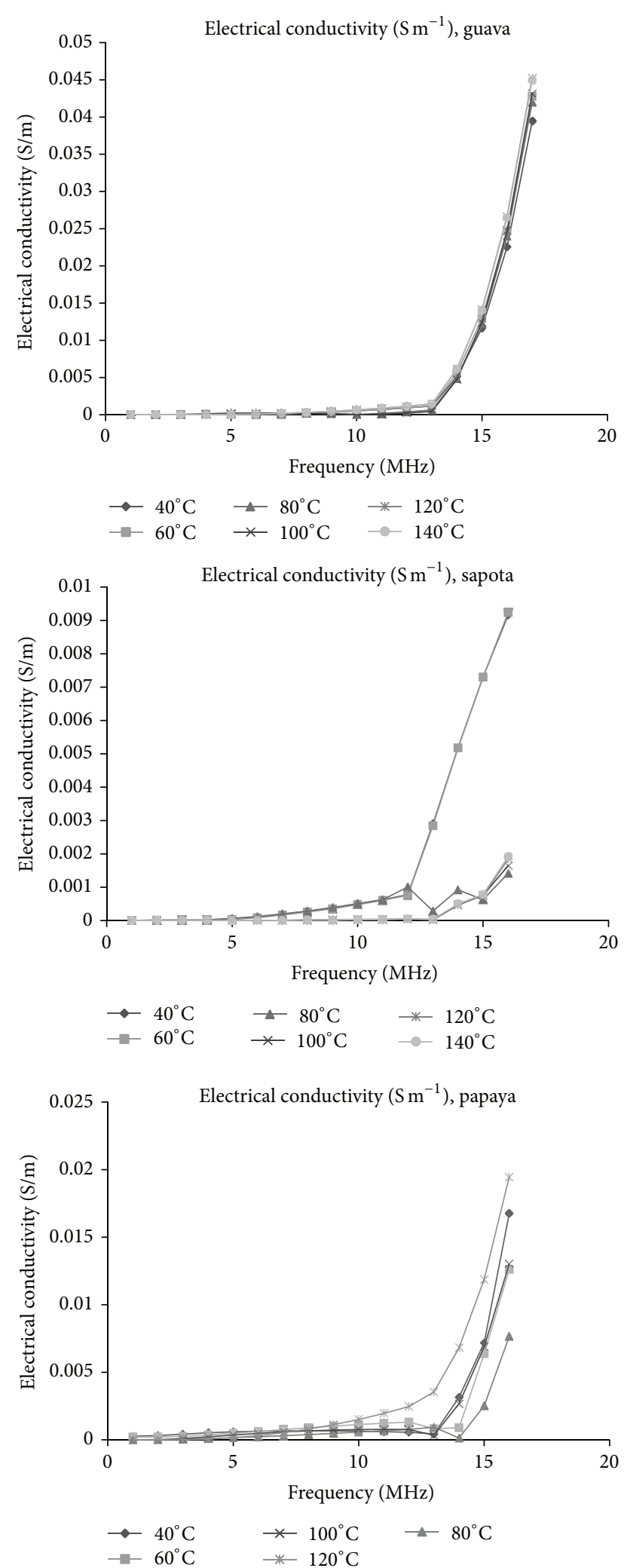

FIGURE 2: Dependence of electrical conductivity on frequency for guava, sapota, and papaya.

The maximum values achieved were $0.0449\left(140^{\circ} \mathrm{C}\right), 0.0155$ $\left(60^{\circ} \mathrm{C}\right)$, and $0.025\left(120^{\circ} \mathrm{C}\right)$ for guava, sapota, and papaya, at frequency of $5 \mathrm{MHz}$. This corresponds to an approximate increase by $6.3,11.2$, and 15.54 times in the electrical conductivities of guava, sapota, and papaya from $1 \mathrm{MHz}$ to $5 \mathrm{MHz}$. From $0.001 \mathrm{MHz}$ to $1 \mathrm{MHz}$, there was insignificant increase in electrical conductivities. It may be noted that the highest value of conductivity achieved was for guava followed by papaya and then for sapota which may be due to the difference in their acidity or moisture content, since electrical conductivity depends hugely on the moisture content, as stated by Sipahioglu and Barringer [7], Sharma and Prasad [10], Venkatesh and Raghavan [19], Feng et al. [24], Nelson and Datta [12], Mugdett and Goldblith [25], Funebo and Ohlsson [26], and many others. There was not much variation of electrical conductivity with temperature at very low frequencies, below $1 \mathrm{MHz}$, after which the conductivity showed higher values for higher temperature at $120^{\circ} \mathrm{C}$ and $140^{\circ} \mathrm{C}$; the conductivity increases with increasing temperature, highest value for guava being $0.0449\left(140^{\circ} \mathrm{C}\right)$ and that for papaya being $0.025\left(120^{\circ} \mathrm{C}\right)$ as stated earlier. However, for sapota, the electrical conductivity increased with increasing temperature up to $60^{\circ} \mathrm{C}$ and then decreased with increasing temperature, with its maximum value being $0.0155\left(\mathrm{~S} \mathrm{~m}^{-1}\right)$.

3.3. Frequency Dependence of Dielectric Properties. Dielectric properties, namely, dielectric constant and loss factor values, have previously been studied by Sipahioglu et al. [8], Ryynänen [27], and Lizhi et al. [28] and this study has shown similar trend for all three fruits. Dielectric constants for all three fruits are plotted in Figure 3 against the frequencies. It can be observed that there is a sharp decrease in their values from $0.001 \mathrm{MHz}$ to $0.1 \mathrm{MHz}$. The maximum values obtained were 248.43 (at $80^{\circ} \mathrm{C}$ ) for guava, 143.99 (at $40^{\circ} \mathrm{C}$ ) for sapota, and 869.79 (at $40^{\circ} \mathrm{C}$ ) for papaya, all at $0.001 \mathrm{MHz}$, which decreased by $2.8,2.68$, and 14.07 times when $0.1 \mathrm{MHz}$ was reached. As the frequency increased, the dielectric constant values did not show much variation till $1 \mathrm{MHz}$. From $1 \mathrm{MHz}$ to $5 \mathrm{MHz}$, as the frequency increased, the dielectric constant gradually decreased up to $49 \%$ for papaya. However, for guava and sapota, dielectric constant increased by $1.41\left(60^{\circ} \mathrm{C}\right)$ and $1.42\left(40^{\circ} \mathrm{C}\right)$ times, respectively. Thus, the overall curves for sapota and guava were roughly " $U$ " shaped, whereas that for papaya was a curve with sharply decreasing values, followed by a lag phase and then a phase of gradual decrease. Effect of temperature on dielectric constant values was the same for guava and papaya where the constants increased with increasing temperature up to $80^{\circ} \mathrm{C}$ and then decreased with the increasing temperature. However, for sapota, the constants decreased steadily with increasing temperature. This was similar to the observation made by Lawrence et al. [29] for hard red winter wheat and Guo et al. [30] for chickpea flour.

Dielectric properties have previously been measured by Jiao et al. [18] and Nelson and Bartley [31] observed that loss factor decreased with increasing frequency but increased with increasing temperature for cowpea weevil, black eyed peas, and mung. Figure 4 represents the dielectric loss factors for the three fruits plotted versus frequency. Much similarly, for all the three fruits, there was an initial phase of sharp 

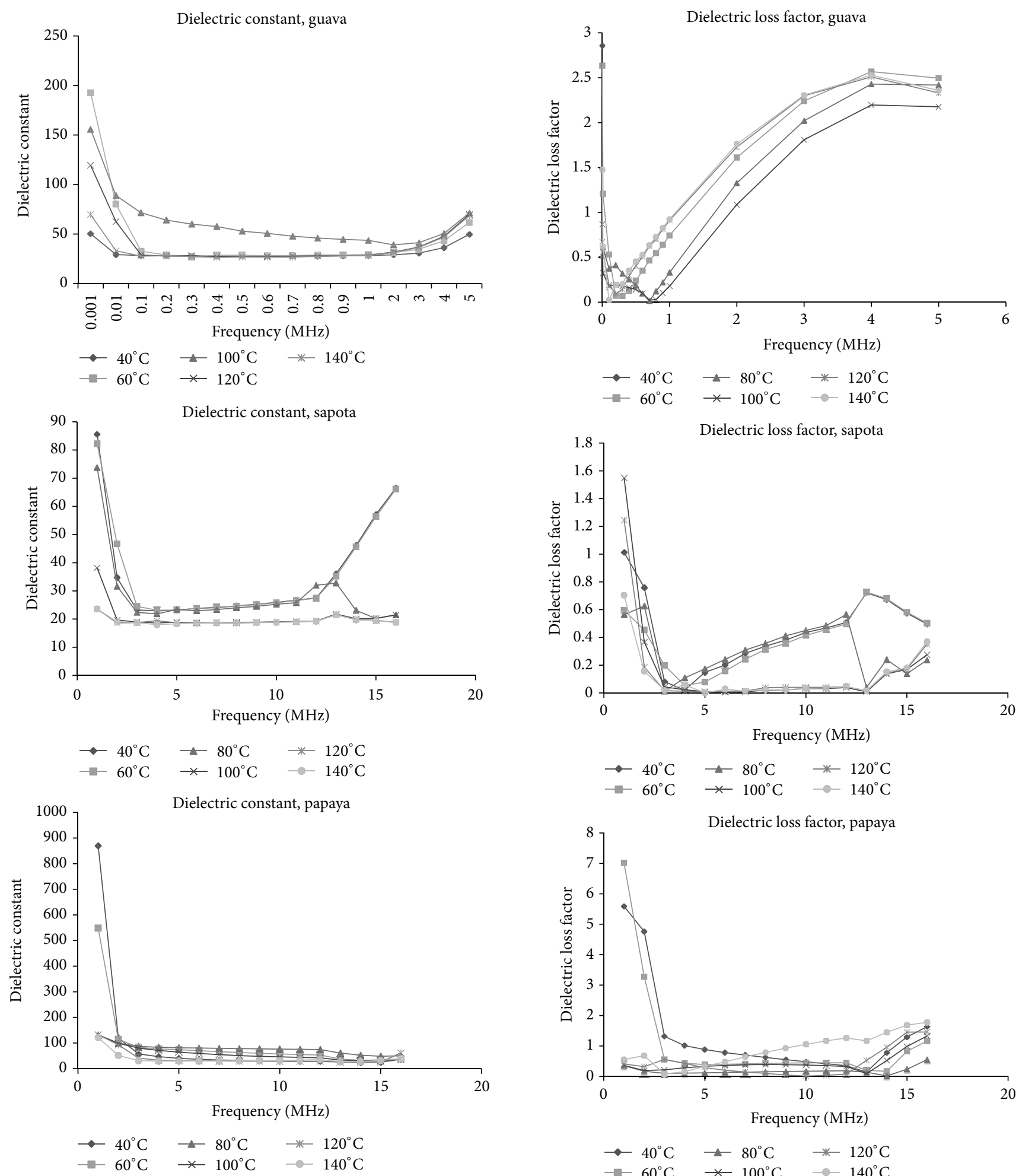

Figure 3: Dependence of dielectric constant on frequency for guava, sapota, and papaya.

decrease but was followed by a gradual and then a sharp increase. For guava, the highest value of loss factor was 9.6859 at $40^{\circ} \mathrm{C}$ for $0.001 \mathrm{MHz}$ and it decreased rapidly to 0.14428 at $0.1 \mathrm{MHz}$. For sapota, the decrease was from 1.54962 to 0.04296 at $100^{\circ} \mathrm{C}$ and for papaya it was from 7.01956 to

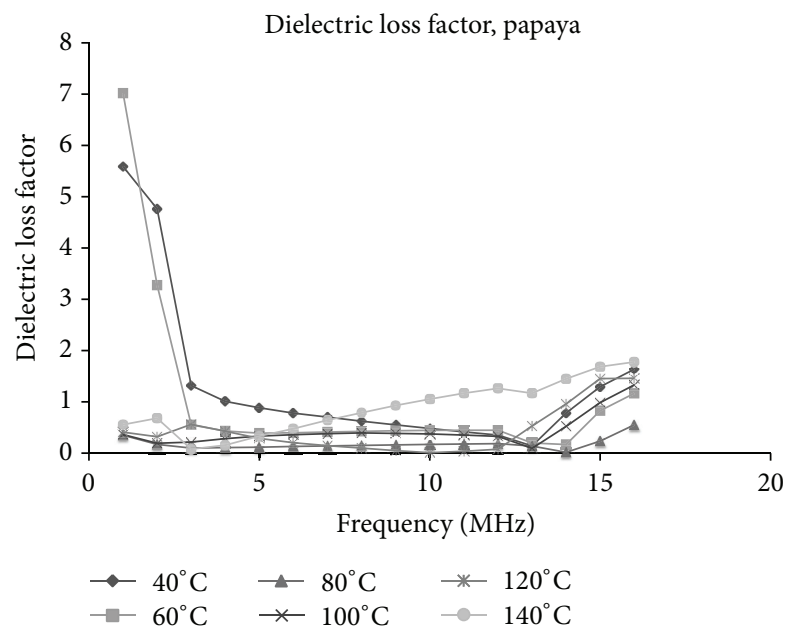

FIgURE 4: Dependence of dielectric loss factor on frequency for guava, sapota, and papaya.

0.55029 at $60^{\circ} \mathrm{C}$ and for both fruits between $0.001 \mathrm{MHz}$ and $0.1 \mathrm{MHz}$. After this, loss factors gradually increased for guava and papaya, but for sapota the dielectric loss was increased to great level at $40^{\circ} \mathrm{C}, 60^{\circ} \mathrm{C}$, and $80^{\circ} \mathrm{C}$. The final phase for 
TABLE 1: Particle size of tropical fruit powder.

\begin{tabular}{|c|c|c|c|c|}
\hline Pos. [ ${ }^{\circ} 2$ Th.] & Height [cts] & FWHM left ['2 Th.] & $d$-spacing $[\AA]$ & Particle size $(\mu \mathrm{m})$ \\
\hline \multicolumn{5}{|c|}{ Particle size of papaya fruit powder } \\
\hline 18.71 & 0.07 & 0.84 & 4.74 & 0.17 \\
\hline 20.09 & 38.29 & 0.30 & 4.41 & 0.46 \\
\hline 28.61 & 28.44 & 0.24 & 3.11 & 0.59 \\
\hline \multicolumn{5}{|c|}{ Particle size of guava fruit powder } \\
\hline 18.60 & 8.99 & 0.39 & 4.76 & 0.37 \\
\hline 19.68 & 8.38 & 0.49 & 4.50 & 0.28 \\
\hline 25.23 & 13.90 & 0.39 & 3.52 & 0.36 \\
\hline \multicolumn{5}{|c|}{ Particle size of sapota fruit powder } \\
\hline 15.61 & 35.17 & 0.72 & 5.67 & 0.19 \\
\hline 50.17 & 14.61 & 0.36 & 1.81 & 0.42 \\
\hline
\end{tabular}

all three fruits showed an upward curve, maximum values of the curve being at $4 \mathrm{MHz}$, with values finally decreasing at $5 \mathrm{MHz}$. For all three fruits, the dielectric loss was more at lower temperatures and decreased as the temperature increased, but, after $1 \mathrm{MHz}$, the loss increased with the increasing temperature. Such results were also reported by Sharma and Prasad [10] for garlic powder.

3.4. FTIR Analysis of Freeze Dried Tropical Fruits Powder. The FTIR analysis of guava, sapota, and papaya powder is shown in Figure 5.

Peaks in the range $650-510 \mathrm{~cm}^{-1}$ are assigned to $\mathrm{C}-\mathrm{Br}$ stretch-alkylhalides; sharp peak is absorbed at 546 and $586 \mathrm{~cm}^{-1}$ in sapota, 536, 579, and $637 \mathrm{~cm}^{-1}$ in guava, and $584 \mathrm{~cm}^{-1}$ in papaya; the peak may also be due to C-I stretch or $\mathrm{C}-\mathrm{Cl}$ stretch. Peak at $772 \mathrm{~cm}^{-1}$ in guava may be assigned to ethyl branch-ethylene butane. Peak at $816 \mathrm{~cm}^{-1}$ in all the three fruits may be assigned to $\mathrm{N}-\mathrm{H}$ to broad loop bending or $\mathrm{CH}_{3}$ rocking. Peak at $1061 \mathrm{~cm}^{-1}$ in guava, $1063 \mathrm{~cm}^{-1}$ in sapota, and $1070 \mathrm{~cm}^{-1}$ is assigned to $\mathrm{C}-\mathrm{N}$ stretch, aliphatic amines or aryl bromides, or aryl chloride or C-O stretch. Peak at $1256 \mathrm{~cm}^{-1}$ that is noticed in all three fruits may be assigned to $\mathrm{P}=\mathrm{O}$ stretch or aryl fluorides. $\mathrm{C}=\mathrm{C}$ stretch appears in the range of $1750-1735 \mathrm{~cm}^{-1}$; there appears a peak at $1746 \mathrm{~cm}^{-1}$ for sapota and $1745 \mathrm{~cm}^{-1}$ for guava. Peak around $2900 \mathrm{~cm}^{-1}$ which is noticed in all three fruits may be due to asymmetric aliphatic $\mathrm{C}-\mathrm{H}$ stretching vibrations of methylene $\left(-\mathrm{CH}_{2}\right)$. Peak in the range of $3500-3000 \mathrm{~cm}^{-1}$ is assigned to $\mathrm{N}-\mathrm{H}$ stretch; peak in this region is noticed in all the three fruits. The bands in the region $900-1153 \mathrm{~cm}^{-1}$ are assigned to $\mathrm{C}-\mathrm{O}$ and C-C stretching modes, while those in the $1400-1199 \mathrm{~cm}^{-1}$ region are due to $\mathrm{O}-\mathrm{C}-\mathrm{H}, \mathrm{C}-\mathrm{C}-\mathrm{H}$, and $\mathrm{C}-\mathrm{O}-\mathrm{H}$ bending vibrational modes of the carbohydrates; similar results are also reported by Leopold et al. [17] in fruit juices. Fructose has a specific maximum peak at $1063 \mathrm{~cm}^{-1}$, which is noticed in all three fruits. Peaks in the region from 3700 to $3000 \mathrm{~cm}^{-1}$ correspond to water and $\mathrm{OH}$ absorption frequencies [32]. The IR spectra of dehydrated fruit powders revealed the presence of carboxylic acids. In case of papaya there was broad absorption at $3400 \mathrm{~cm}^{-1}$ which is assigned to $-\mathrm{OH}$ stretching vibrations. In guava a peak at $3369 \mathrm{~cm}^{-1}$ was observed which is also assigned to $-\mathrm{OH}$ stretching. In both papaya and guava the peaks at $2926 \mathrm{~cm}^{-1}$ revealed the possible presence of $\mathrm{CH}$ bonds. The peaks that appear near $1630 \mathrm{~cm}^{-1}$ in papaya powder represent $\mathrm{C}=\mathrm{O}$ stretch and its conjugation with $\mathrm{C}=\mathrm{C}$. The peak marked at $1620 \mathrm{~cm}^{-1}$ in guava powder can be assigned to $\mathrm{N}-\mathrm{H}$ bending for primary and secondary amides. The broad absorption of $\mathrm{C}=\mathrm{O}$ at $1680-1630 \mathrm{~cm}^{-1}$ partially overlaps with $\mathrm{N}-\mathrm{H}$ absorption band at $1640-1620 \mathrm{~cm}^{-1}$. The peak at $1054 \mathrm{~cm}^{-1}$ in both papaya and guava powder is because of $\mathrm{C}-\mathrm{O}$ absorptions indicating the presence of esters. This band is characteristic of carbohydrates, which shows high absorbance between 1250 and $950 \mathrm{~cm}^{-1}$ wavenumber values. The carboxylic acids present may be polygalacturonic acid or related acids [1].

3.5. X-Ray Diffraction Analysis. Crystallization is of great importance for the stability of powdered juice and can be determined by means of X-ray diffraction analysis. The presence of diffuse and large peaks in X-ray diffraction containing amorphous material is due to the fact that, in the amorphous state, the molecules are disorderly displayed producing disperse bands whereas crystalline materials yield sharp and defined peaks since they are presented in a highly ordered state. The X-ray diffraction patterns of papaya, guava, and sapota are shown in Figure 6, respectively. The diffraction peaks observed in the graph are broad, which indicate that the crystallite size is small which was similar to the results obtained by Theivasanthi and Alagar [14]. The particle size of each fruit powder has been determined using Debye-Scherrer formula:

$$
\tau=\frac{K \lambda}{\beta \cos \theta} .
$$

$K$ is the shape factor, $\lambda$ is the $\mathrm{X}$-ray wavelength, $\beta$ is the line broadening at half the maximum intensity in radians, and $\theta$ is the Bragg angle; $\tau$ is the mean size of the ordered (crystalline) domains, which may be smaller than or equal to the grain size. The average particle sizes of papaya, guava, and sapota were found to be $0.411 \mu \mathrm{m}, 0.339 \mu \mathrm{m}$, and $0.309 \mu \mathrm{m}$, respectively, and were represented in Table 1 . Starch is a semicrystalline 


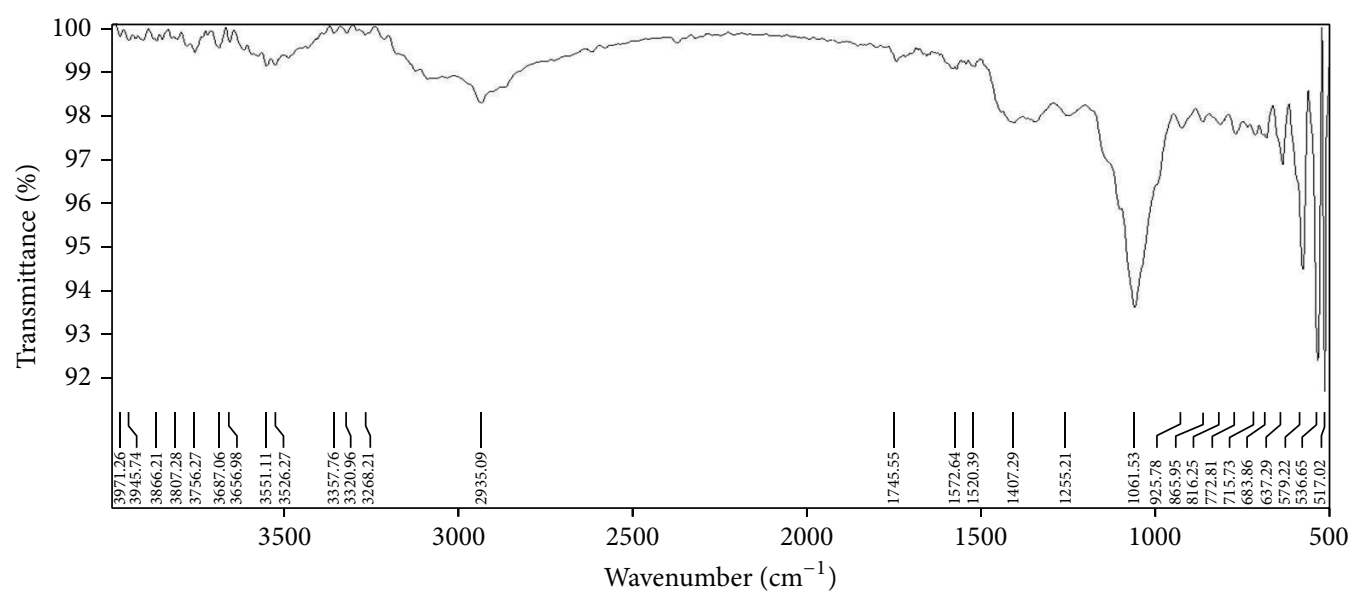

(a) Guava

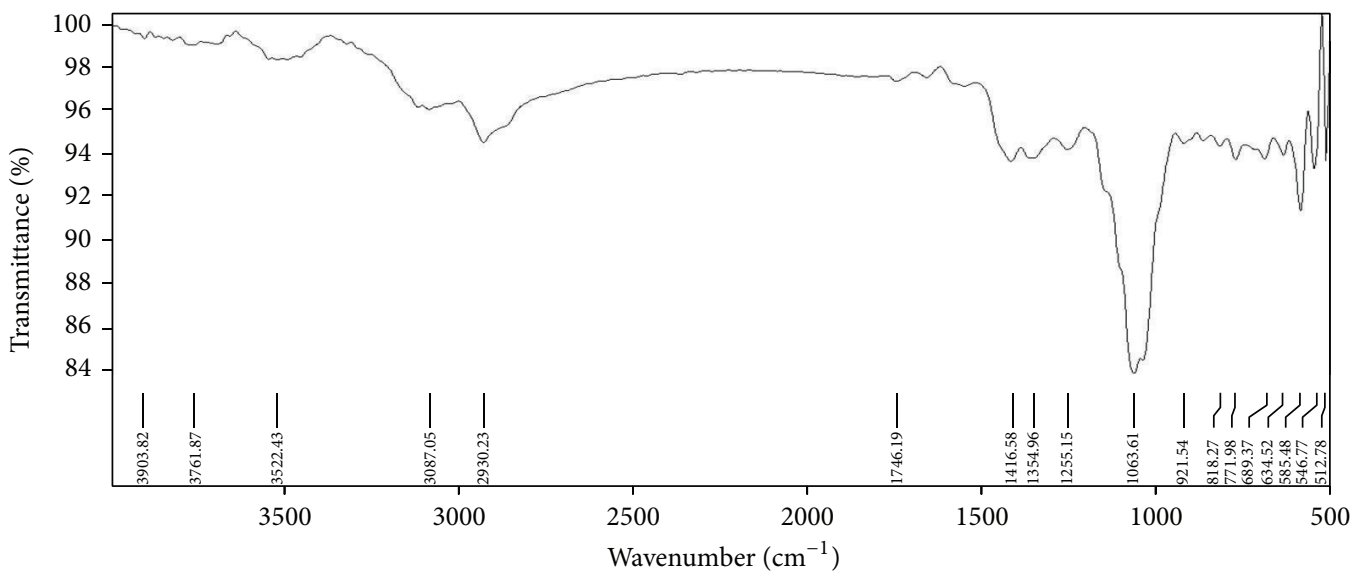

(b) Sapota

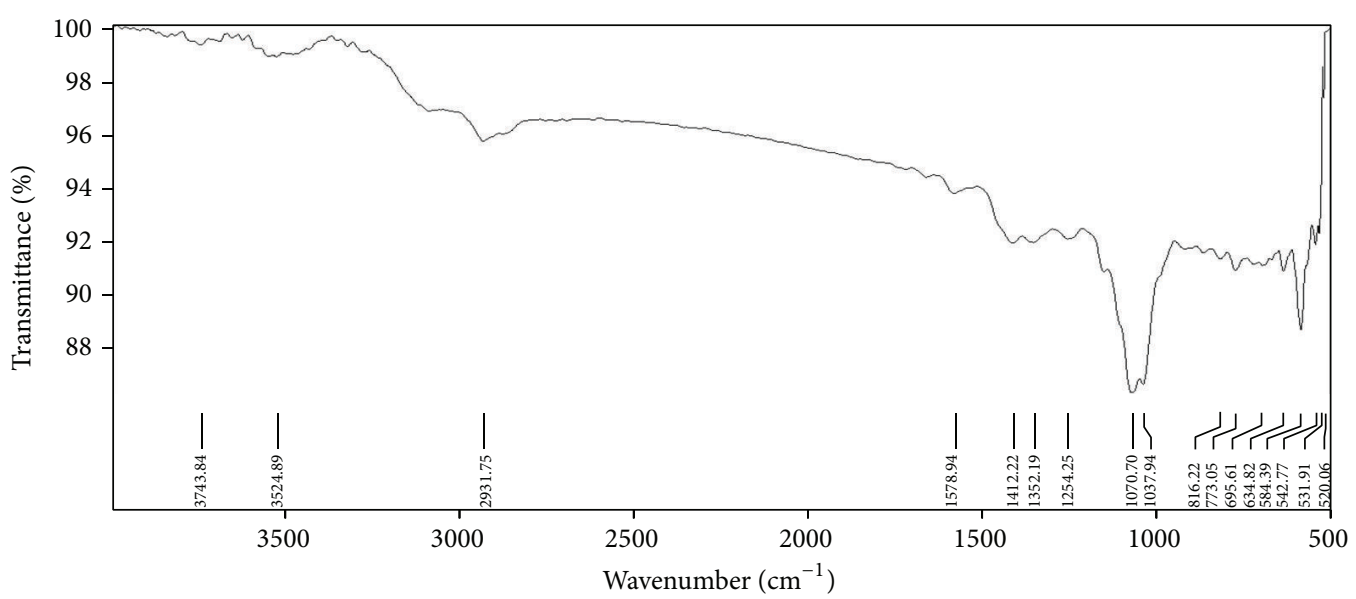

(c) Papaya

FIGURE 5: FTIR spectra of guava (a), sapota (b), and papaya (c).

material. Actually the crystalline order of starch granules is lost during gelatinization. The semicrystalline structure can be identified at the light microscope level and through characteristic $\mathrm{X}$-ray diffraction patterns. There are four major types of X-ray diffraction patterns of native starches, namely,
A, B, C, and V [32]. The A form starch is mainly present in cereal starches, such as maize starch and wheat starch. The XRD patterns of these starches give the stronger diffraction peaks at around $15,17,18$, and $23^{\circ}$. The B form starch is usually available in tuber starch such as potato and this type 


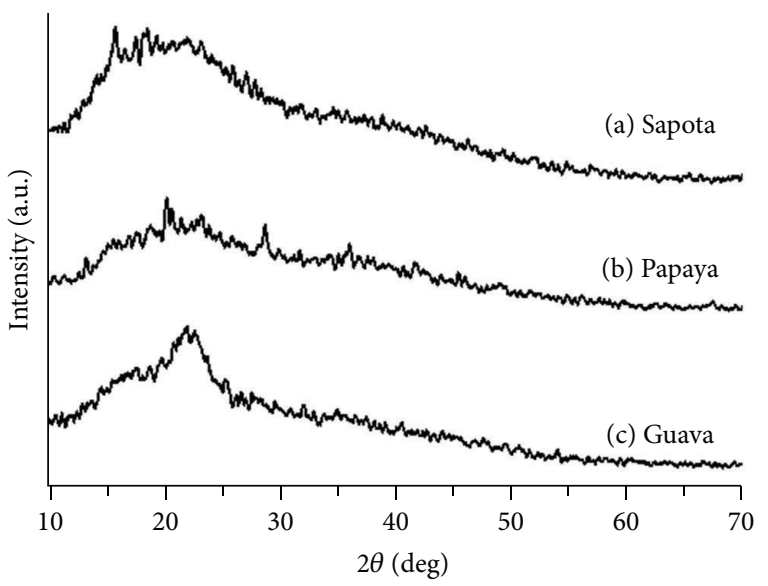

FIGURE 6: XRD of sapota (a), papaya (b), and guava (c).

of starch gives the strongest diffraction peak at $17^{\circ} 2 \theta$. There were also few small peaks at around $2 \theta$ values of 20,22 , and $24^{\circ}$. The C pattern starch is a mixture of both A and B types, such as smooth seeded pea starch and various bean starches [33]. In papaya, the peaks were found at $18^{\circ}$ and $28^{\circ}$ at $2 \theta$ angle indicating the presence of A-type starch. A peak was also recorded at $20^{\circ}$ showing the possibility of C-type starch. In case of guava, a sharp peak at $18^{\circ}$ was observed at $2 \theta$ angle. This shows the presence of type A starch. Other peaks were also noted at $19^{\circ}$ and $25^{\circ}$. Similarly, in the case of sapota, a sharp peak was observed at $15^{\circ}$ which again stresses the presence of A-type starch. The presence of A-type starch indicates that the semicrystalline nature of starch present in the fruit is not destructed after dehydration process.

3.6. SEM Image Analysis. The freeze dried powder of guava and sapota is free flowing, whereas the papaya powder is sticky, which may be due to the presence of pectin in papaya. SEM technique was considered to be a powerful tool for determining and observing the caking phenomenon on the powder surface. SEM micrographs for papaya, guava, and sapota powder were shown in Figures 7(a), 7(b), and 7 (c). In morphological terms, two phases were observed in both guava and sapota solids: a lamellar surface structure (with flake form) and a spherical arrangement. These two morphologies indicate a possible separation of phases in the solids as a result of the dehydration processes. The interactions between the structural components on the surface of these materials can be understood as a surface tension increase, which lead to the separation and formation of spherical particles from the largely containing-pectin layered surface. However, papaya powder formed sponge platelets upon freeze-drying, which is also shown in the SEM image of papaya.

\section{Conclusion}

The TGA-DSC showed the thermal stability of guava powder, when compared to sapota and papaya powder. All the three fruits showed very low electrical conductivity at

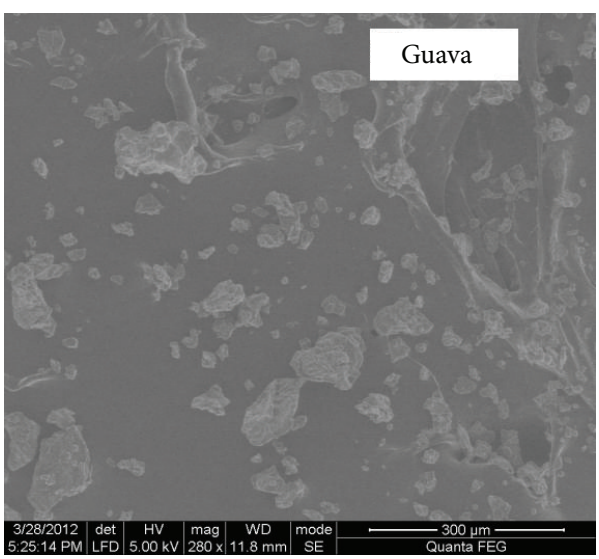

(a)

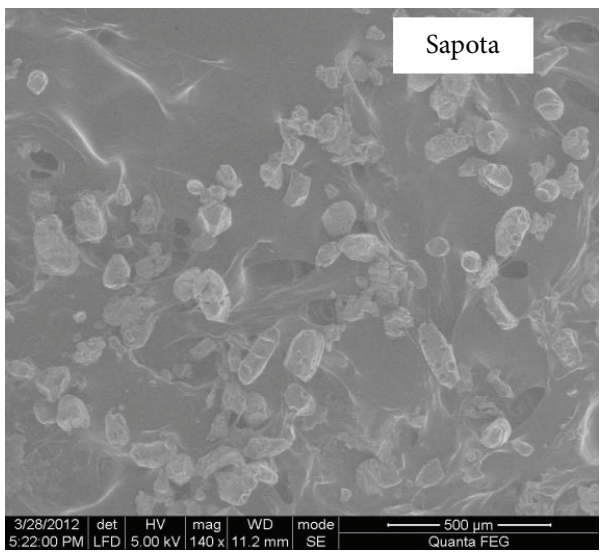

(b)

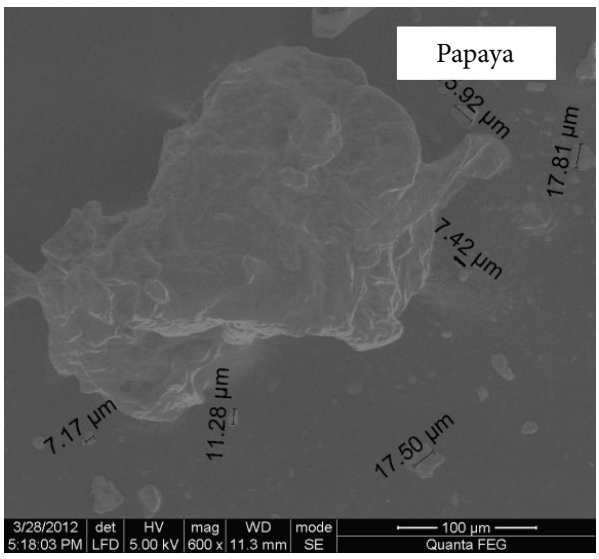

(c)

FIgURE 7: SEM images of guava (a), sapota (b), and papaya (c).

frequency between $0.001 \mathrm{MHz}$ and $1 \mathrm{MHz}$. However, after $1 \mathrm{MHz}$, the electrical conductivities increased sharply. Effect of temperature on dielectric constant values was the same for guava and papaya where the dielectric constants increased with increasing temperature up to $80^{\circ} \mathrm{C}$ and then decreased with the increasing temperature. However, for sapota, the constants decreased steadily with increasing temperature. FTIR showed presence of chlorides and $\mathrm{O}-\mathrm{H}$ and $\mathrm{N}-\mathrm{H}$ bonds 
in guava, chloride and $\mathrm{CH}$ bond in papaya, and chlorides and $\mathrm{C}=\mathrm{O}$ and $\mathrm{C}-\mathrm{H}$ bonds in sapota. The presence of A-type starch in all the three fruits indicates that the semicrystalline nature of starch present in the fruit is not destructed after dehydration process.

\section{Conflict of Interests}

The authors declare that there is no conflict of interests regarding the publication of this paper.

\section{References}

[1] C. Osorio, J. G. Carriazo, and H. Barbosa, "Thermal and structural study of guava (Psidium Guajava L) powders obtained by two dehydration methods," Química Nova, vol. 34, no. 4, pp. 636-640, 2011.

[2] R. S. Chaughule, P. C. Mali, R. S. Patil, G. D. Joshi, and Y. M. Lo, "Magnetic resonance spectroscopy study of sapota fruits at various growth stages," Innovative Food Science and Emerging Technologies, vol. 3, no. 2, pp. 185-190, 2002.

[3] R. M. Maggio, L. Cerretani, C. Barnaba, and E. Chiavaro, "Application of differential scanning calorimetry-chemometric coupled procedure to the evaluation of thermo-oxidation on extra virgin olive oil," Food Biophysics, vol. 7, no. 2, pp. 114-123, 2012.

[4] C. P. Tan and Y. B. Che Man, "Recent developments in differential scanning calorimetry for assessing oxidative deterioration of vegetable oils," Trends in Food Science and Technology, vol. 13, no. 9-10, pp. 312-318, 2002.

[5] B. Kowalski, "Thermal-oxidative decomposition of edible oils and fats. DSC studies," Thermochimica Acta, vol. 184, no. 1, pp. 49-57, 1991.

[6] I. M. de Rosa, J. M. Kenny, D. Puglia, C. Santulli, and F. Sarasini, "Morphological, thermal and mechanical characterization of okra (Abelmoschus esculentus) fibres as potential reinforcement in polymer composites," Composites Science and Technology, vol. 70, no. 1, pp. 116-122, 2010.

[7] O. Sipahioglu and S. A. Barringer, "Dielectric properties of vegetables and fruits as a function of temperature, ash, and moisture content," Journal of Food Science, vol. 68, no. 1, pp. 234239, 2003.

[8] O. Sipahioglu, S. A. Barringer, I. Taub, and A. Prakash, "Modeling the dielectric properties of ham as a function of temperature and composition," Journal of Food Science, vol. 68, no. 3, pp. 904-909, 2003.

[9] M. Soltani, R. Alimardani, and M. Omid, "Evaluating banana ripening status from measuring dielectric properties," Journal of Food Engineering, vol. 105, no. 4, pp. 625-631, 2011.

[10] G. P. Sharma and S. Prasad, "Dielectric properties of garlic (Allium sativum L.) at $2450 \mathrm{MHz}$ as function of temperature and moisture content," Journal of Food Engineering, vol. 52, no. 4, pp. 343-348, 2002.

[11] X. Li, A. S. Zyuzin, and A. V. Mamishev, "Measuring moisture content in cookies using dielectric spectroscopy," in Proceedings of the IEEE Conference on Electrical Insulation and Dieletric Phenomena, pp. 459-462, Albuquerque, NM, USA, October 2003.

[12] S. O. Nelson and A. K. Datta, "Dielectric properties of food materials and electric field interactions," in Handbook of
Microwave Technology for Food Application, pp. 69-114, Marcel Dekker, New York, NY, USA, 2001.

[13] Y. Mizukami, Y. Sawai, and Y. Yamaguchi, "Moisture content measurement of tea leaves by electrical impedance and capacitance," Biosystems Engineering, vol. 93, no. 3, pp. 293-299, 2006.

[14] T. Theivasanthi and M. Alagar, "An insight analysis of nano sized powder of jackfruit seed," Nano Biomedicine and Engineering, vol. 3, no. 3, pp. 163-168, 2011.

[15] M. Deraman, S. Zakaria, M. Husin et al., "X-ray diffraction studies on fiber of oil palm empty fruit bunch and rubberwood for medium-density fiberboard," Journal of Materials Science Letters, vol. 18, no. 3, pp. 249-253, 1999.

[16] K. Rengsutthi and S. Charoenrein, "Physico-chemical properties of jackfruit seed starch (Artocarpus heterophyllus) and its application as a thickener and stabilizer in chilli sauce," $L W T$ Food Science and Technology, vol. 44, no. 5, pp. 1309-1313, 2011.

[17] L. F. Leopold, N. Leopold, H.-A. Diehl, and C. Socaciu, "Quantification of carbohydrates in fruit juices using FTIR spectroscopy and multivariate analysis," Spectroscopy, vol. 26, no. 2, pp. 93-104, 2011.

[18] S. Jiao, J. A. Johnson, J. Tang, G. Tiwari, and S. Wang, "Dielectric properties of cowpea weevil, black-eyed peas and mung beans with respect to the development of radio frequency heat treatments," Biosystems Engineering, vol. 108, no. 3, pp. 280-291, 2011.

[19] M. S. Venkatesh and G. S. V. Raghavan, "An overview of microwave processing and dielectric properties of agri-food materials," Biosystems Engineering, vol. 88, no. 1, pp. 1-18, 2004.

[20] S. N. Jha and S. Gunasekaran, "Authentication of sweetness of mango juice using Fourier transform infrared-attenuated total reflection spectroscopy," Journal of Food Engineering, vol. 101, no. 3, pp. 337-342, 2010.

[21] L. M. Pereira, S. M. Carmello-Guerreiro, and M. D. Hubinger, "Microscopic features, mechanical and thermal properties of osmotically dehydrated guavas," LWT-Food Science and Technology, vol. 42, no. 1, pp. 378-384, 2009.

[22] U. Einhorn-Stoll and H. Kunzek, "Thermoanalytical characterisation of processing-dependent structural changes and state transitions of citrus pectin," Food Hydrocolloids, vol. 23, no. 1, pp. 40-52, 2009.

[23] M. Iijima, K. Nakamura, T. Hatakeyama, and H. Hatakeyama, "Phase transition of pectin with sorbed water," Carbohydrate Polymers, vol. 41, no. 1, pp. 101-106, 2000.

[24] H. Feng, J. Tang, and R. P. Cavalieri, "Dielectric properties of dehydrated apples as affected by moisture and temperature," Transactions of the American Society of Agricultural Engineers, vol. 45, no. 1, pp. 129-135, 2002.

[25] R. E. Mugdett and S. Goldblith, "Dielectric behavior of a semisolid food at low, intermediate and high moisture contents," Journal of Microwave Power, vol. 15, pp. 27-36, 1980.

[26] T. Funebo and T. Ohlsson, "Dielectric properties of fruits and vegetables as a function of temperature and moisture content," Journal of Microwave Power and Electromagnetic Energy, vol. 34, no. 1, pp. 42-54, 1999.

[27] S. Ryynänen, "The electromagnetic properties of food materials: a review of the basic principles," Journal of Food Engineering, vol. 26, no. 4, pp. 409-429, 1995.

[28] H. Lizhi, K. Toyoda, and I. Ihara, "Dielectric properties of edible oils and fatty acids as a function of frequency, temperature, moisture and composition," Journal of Food Engineering, vol. 88, no. 2, pp. 151-158, 2008. 
[29] K. C. Lawrence, S. O. Nelson, and P. G. Bartley Jr., "Measuring dielectric properties of hard red winter wheat from 1 to $350 \mathrm{MHz}$ with a flow-through coaxial sample holder," Transactions of the American Society of Agricultural Engineers, vol. 41, no. 1, pp. 143150, 1998.

[30] W. Guo, G. Tiwari, J. Tang, and S. Wang, "Frequency, moisture and temperature-dependent dielectric properties of chickpea flour," Biosystems Engineering, vol. 101, no. 2, pp. 217-224, 2008.

[31] S. O. Nelson and P. G. Bartley Jr., "Measuring frequency- and temperature-dependent dielectric properties of food materials," Transactions of the American Society of Agricultural Engineers, vol. 43, no. 6, pp. 1733-1736, 2000.

[32] C. Zhang, X. Liu, H. Qiang et al., "Inhibitory effects of rosa roxburghii tratt juice on in vitro oxidative modification of low density lipoprotein and on the macrophage growth and cellular cholesteryl ester accumulation induced by oxidized low density lipoprotein," Clinica Chimica Acta, vol. 313, no. 1-2, pp. 37-43, 2001.

[33] C. Adina, F. Florinela, T. Abdelmoumen, and S. Carmen, "Application of FTIR spectroscopy for a rapid determination of some hydrolytic enzymes activity on sea buckthorn substrate," Romanian Biotechnological Letters, vol. 15, no. 6, pp. 5738-5744, 2010. 

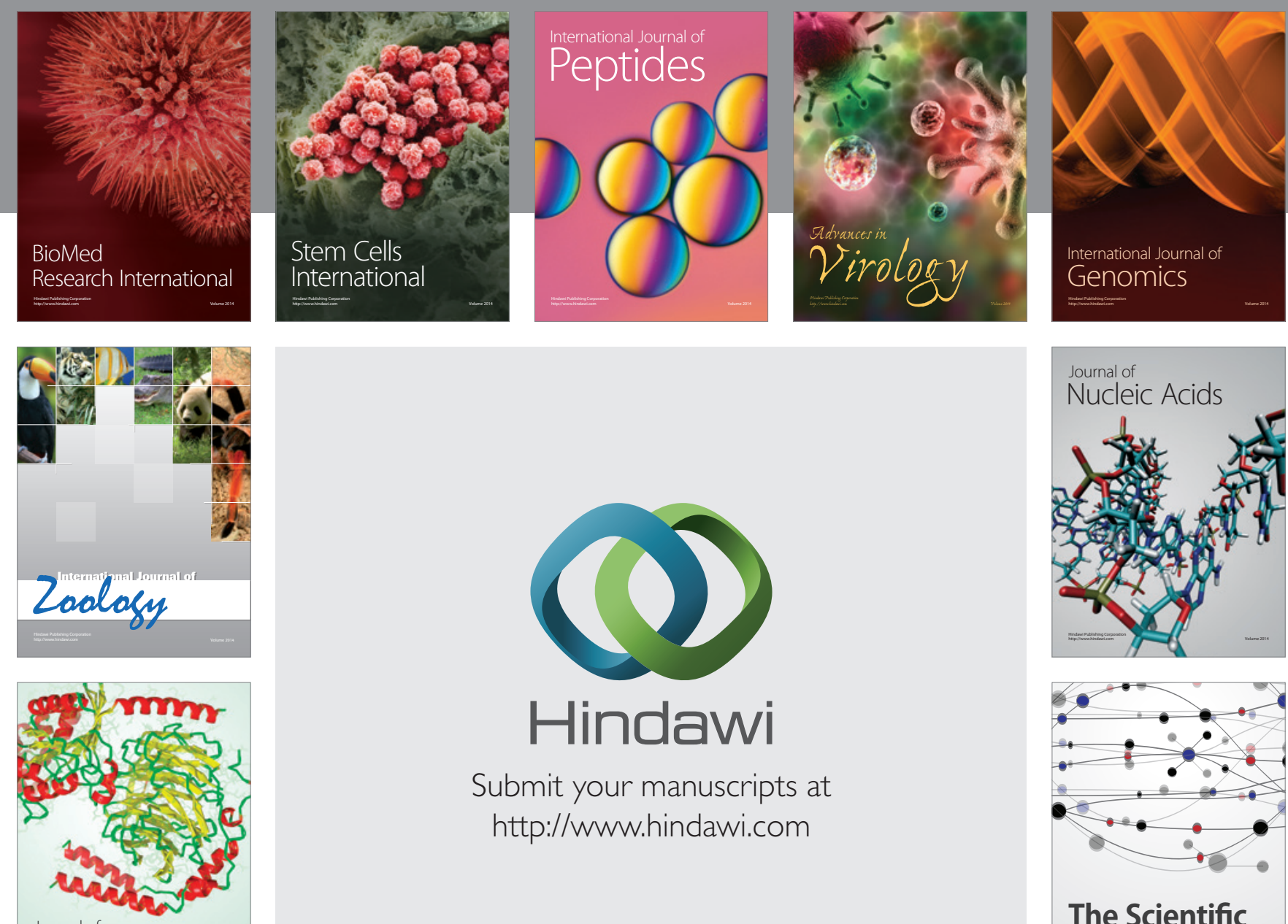

Submit your manuscripts at

http://www.hindawi.com

Journal of
Signal Transduction
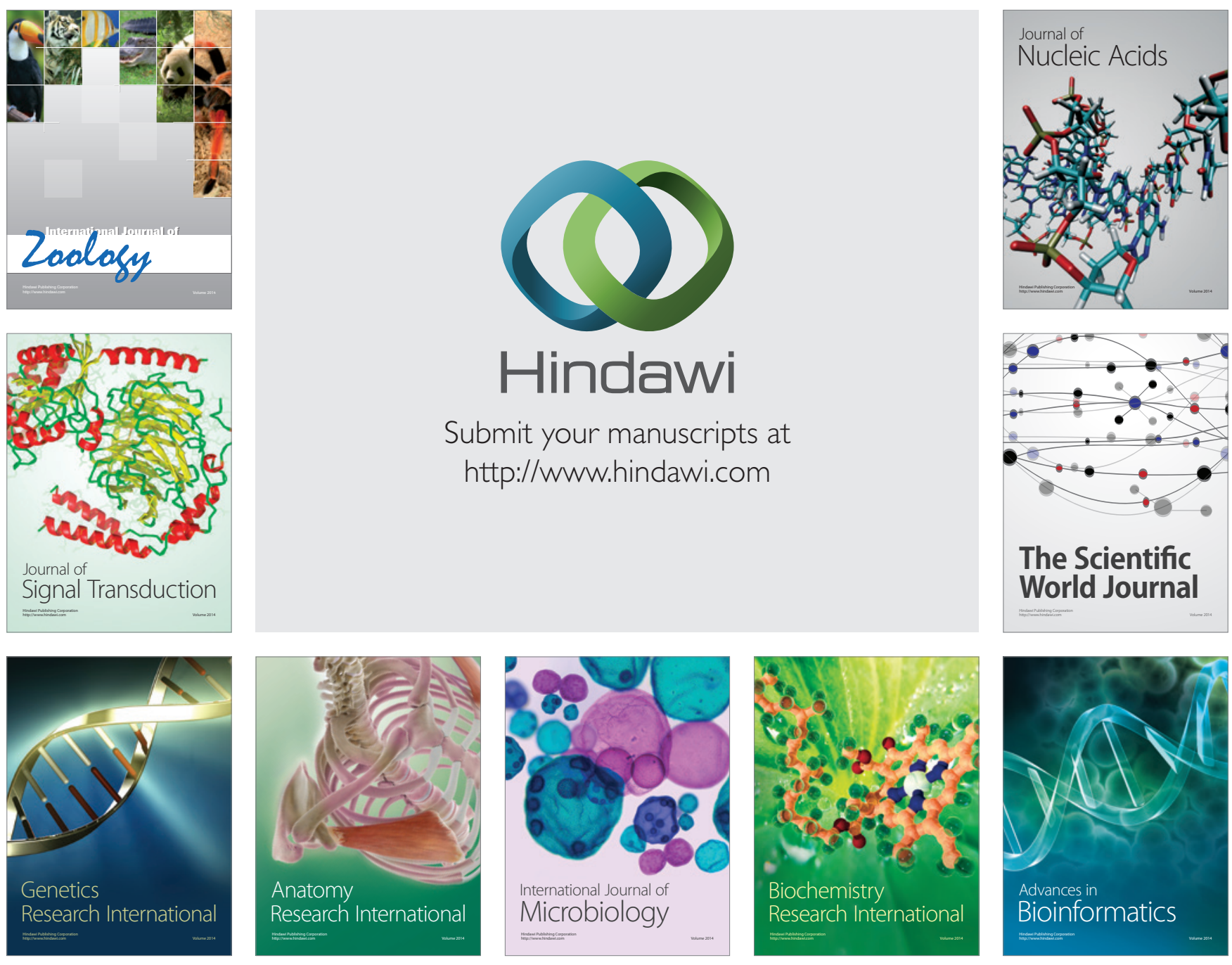

The Scientific World Journal
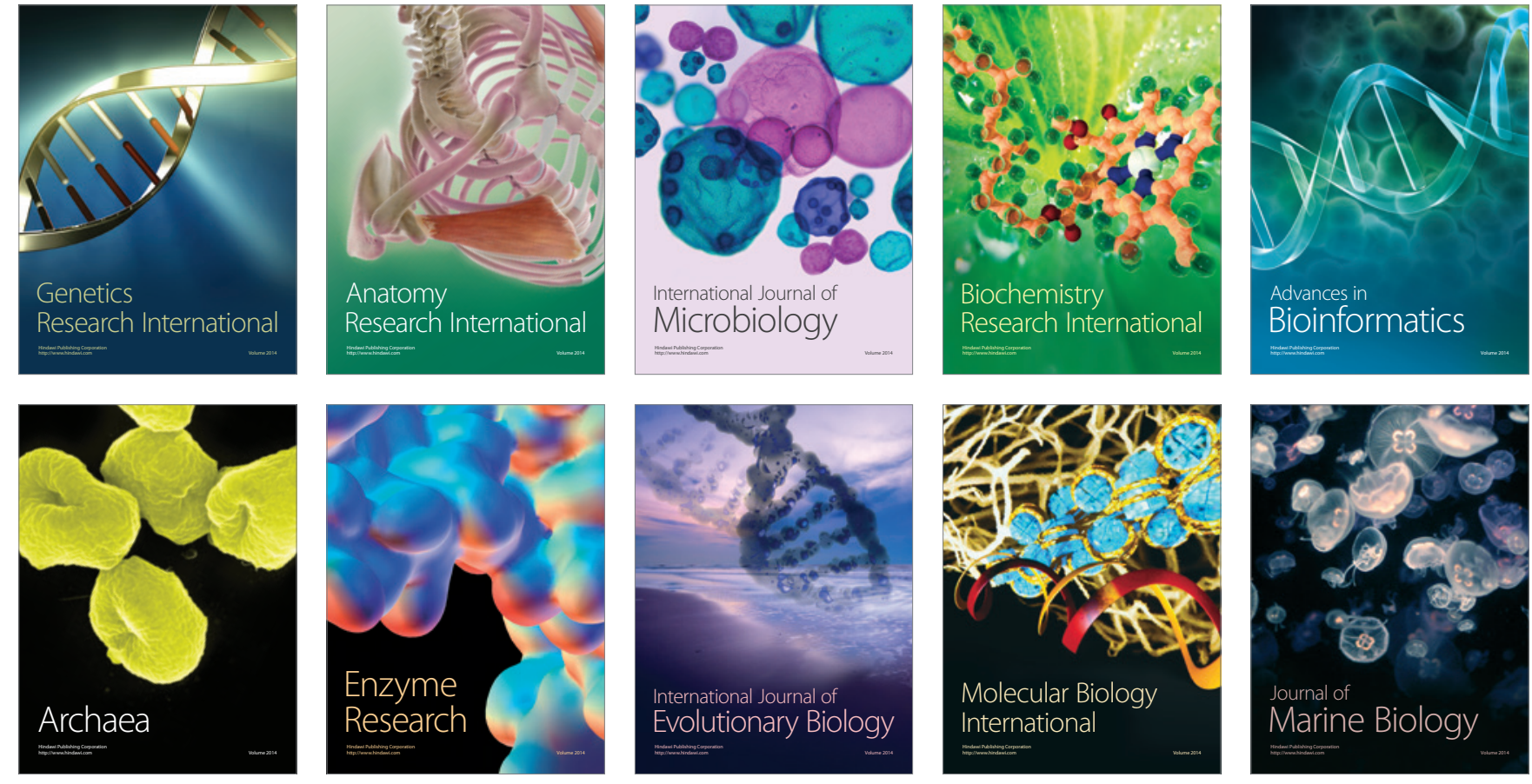